\title{
Attitudes of tennis coaches towards continuous education - a Caribbean perspective
}

\author{
Kyle A. Hannays
}

ABSTRACT

This study sought to unearth the attitudes of Caribbean Tennis coaches towards continuous education. Utilizing purposeful sampling, forty (40) respondents of assorted coaching levels from various islands were recruited to participate in the study. The results illustrated that, contrary to belief, coaches did not view continuous education negatively but rather illuminated that courses may not be adequately catering to the needs of coaching practitioners in a meaningful way. Additionally, results also highlighted issues such as inadequate exposure and disgruntlement of coaches who feel undervalued. As such, strategies must be focused on addressing these issues.
Key words: coaching, education, attitudes, experience.

Received: 10 January 2020

Accepted: 14 February 2020

Corresponding author: Kyle A. Hannays, Trinidad and Tobago.

Email: kahannays@hotmail.com

\section{INTRODUCTION}

'The concept of coaching education has been gaining traction within the athletic sphere. Coaching education is a developmental strategy which sees the coach assume the role of learner within an environment geared towards achieving a specific personal or professional goals; this is facilitated through the provision of training and/or guidance (VargasTonsing, 2007). This process of coach education has been identified by several researchers as key to "raising the standard of coaching practice" (Avner et al., 2017, p. 101). Yet despite the reported consensus above, coaching education as a developmental initiative for coaching practitioners seems frequently overlooked and undersubscribed within the Caribbean. Most often, experience surfaces as the favoured qualifier in the field. Researchers have noted that while certification is mainly obtained following successful completion of formal coaching education programs, many studies have pointed to the fact that "formalized learning venues are not valued by coaches as much as their day-to-day learning experiences in the field"(Werthner \& Trudel, 2006, pp. 198-199).

Despite this preference noted above, several researchers agree that, "Successful coaches make active attempts to obtain additional knowledge and skills right through their careers as coaches."(Van Der Merwe et al., 2015, p. 2). While this in no way negates the importance of experience to coaching practice, the role of coaching education to this development cannot be ignored. A primary fact that must be highlighted within this discussion refers to the nature of coaching education. Gilbert, Côté and Mallet (2010) aptly point out that coaching competency occurs via both formal and informal educational environments; such as observation (Cushion et al., 2003, p. 217), and mentorship (Bloom, DurandBush, Schinke, \& Salmela, 1998). Furthermore, Nelson, Groom and Potrac (2014) aptly highlight that knowledge can be either propositional/theoretical (knowing-that) or practical/performative (knowing-how). They also highlight that the nature of the practical knowledge (weak or strong) is a significant issue since in the weak sense, one can perform a task but cannot articulate how it is done while in the strong sense, one can both execute and articulate the process (Nelson et al., 2014, p. 10). This distinction within practical knowledge inadvertently highlights that experience alone may not be sufficient and lends validity to the argument in favour of more structured coaching education.

While coaching education in its many forms seem to be growing in significance and engagement, an observation evidenced by the existence of substantial literature on the subject, tennis coaching within the Trinidad and Tobago remains a practice that mandates no qualification. Though no shortage of talent exists within both coaches and athletes alike, development seems almost stunted and performance outcomes remain less than favourable. This reality is not only true for Trinidad and Tobago tennis but also within the wider Central American \& Caribbean Tennis Confederation (COTECC). Even more alarming is the fact that when developmental courses are offered, they are very poorly attended by the region's coaches. It would seem therefore, that despite its increasing relevance, many tennis coaches within the Caribbean seem content with base level coaching qualification or none at all. This study therefore sought to explore the attitudes of Caribbean tennis coaches towards continuous coaching education, in an attempt to learn how it may influence tennis success in the Caribbean. 


\section{METHODOLOGY}

Given the nature of the research, a mixed methods approach was adopted; a modified Coaching Education questionnaire (Vargas-Tonsing, 2007) and semi-structured interviews were utilized. The questionnaire sample was purposefully recruited via the ITF development officer who served as gatekeeper for the study; selection was based on the educational level of coaches. Following the questionnaires, interviews were conducted with four coaches whose selection was influenced by their coaching level, experience and geographic location. The criteria for selection was as follows: A play tennis coach with less than two years of experience, a Level 1 coach with more than five years of experience, a Level 2 coach with ten or more years of experience and the single level three coach within the region who has over fifteen (15) years of experience. Each coach represented a different island within the Caribbean.

\section{DATA TREATMENT/ANALYSIS}

Responses to the coaching education questionnaire were analyzed to elucidate any dominance or lack thereof among the investigated topics, motivators and attitudes. The results were measured comparatively using the mean of the responses given within the 5-point Likert scale with the general consensus of the participant coaches with regards to the subjects noted. Following this exploration, interview questions were constructed and general talking points noted for reference during the semi- structured interviews. Interviews were recorded and a partial transcription was done during which subsequent commonalities were identified and extracted for further exploration. Findings of the questionnaires were also compared to the thematic commonalities identified during the analysis of the interviews.

\section{RESULTS}

Fifteen coaching education topics were outlined, and participants were asked to rate each topic in terms of how helpful they felt the subject would be to their practice of coaching. Among the highlighted subjects, Sport Nutrition $(M=4.51)$, Goal setting $(M=4.45)$ and Communication $(M=4.42$ on a 5-point Likert Scale, were topics that generated the greatest interest for coaching education courses. Drugs in sports and addictive behaviours had surprisingly low means given the frequency of drug use among athletes, weighing 2.74 and 3.13respectively (See figure 1).

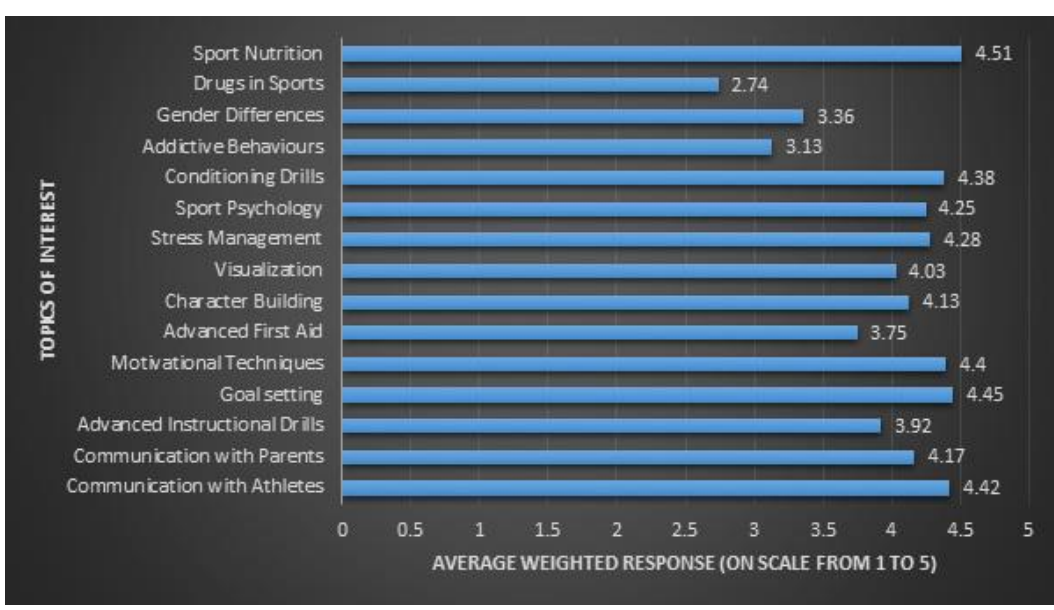

Figure 1. Topics of interest in coach education: weighted average responses from Caribbean coaches.

Additionally, nine motivational factors to coaching education were outlined and participants were asked to rate how significant a role each played in their decision to pursue coaching education. Results showed that relevance of topic $(M=4.0)$ was the most significant factor impacting the participants' decision to engage in continuous coaching education. Also significant to motivation were online availability and desire to coach higher levels having an average of 3.88 and 3.85 respectively. Ranging lowest in consensus was league requirement with a mere average of 2.63; this mean value was reflective of the responses which ranged largely between not important at all (1) and important (3) on the 5-point scale. All related results are included in Figure 2.

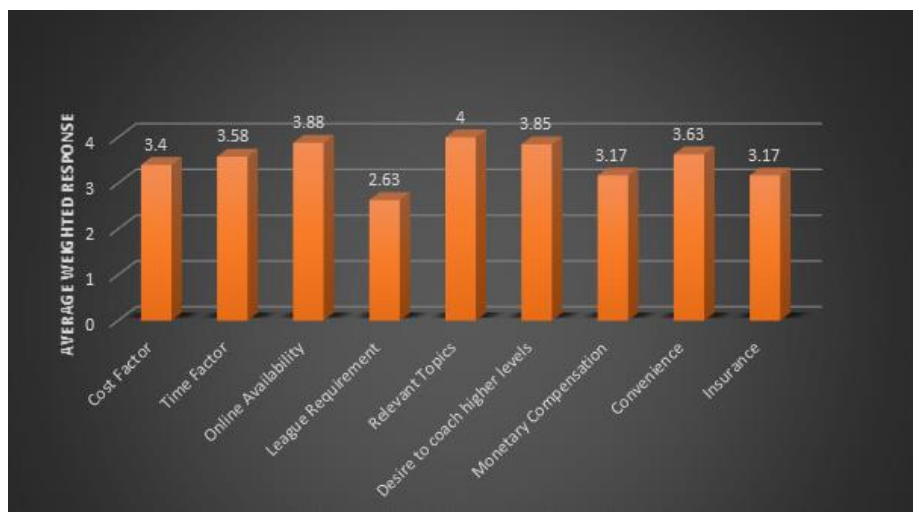

Figure 2. Motivations for engagement in coach education: average weighted responses from Caribbean coaches.

Participants were also asked seven questions aimed at ascertaining their perceptions of coaching education. In general, coaches seemed to recognize the value of continuous coaching education; $100 \%$ of the respondents acknowledged the importance of coaching education to youth sport coaching, $92.5 \%$ felt it should be mandatory while $75 \%$ agreed it should be required. Only $80 \%$ of the respondents planned on pursuing this path with $72.5 \%$ expressing a higher 
likelihood of participation if this education were available online.

Following the questionnaires, the interviews attempted to gain clarity on not only the participants philosophy of coaching but also their views on coaching education and their perspectives on what accounts for the underperformance of the athletes within the region. To this end, highlighted themes among the coaching levels included Compliance of coaching Education and individual philosophy, Online availability and continuity for coaching education, Funding and Coaching education and Experience and coaching education.

\section{DISCUSSION}

A descriptive exploratory analysis was performed on the data presented above in a bid to address the major concerns of this research. Given the results noted above, it seems only fitting to point out that in general, the attitudes of Caribbean tennis coaches towards continuous coaching education are significantly positive. Results of the mixed-methods approach supported an acknowledgement of its value to development; $100 \%$ of the participants agreed that coaching education was important for youth sport coaches, $80 \%$ of which expressed plans to pursue coaching education in the future. However, despite the overwhelming acceptance of its role, several other factors impact the frequency of pursuit. These included compliance of coaching education and individual philosophy, online availability and continuity for coaching education as well as issues related to funding by governing sporting bodies and the perceived value of experience.

The compliance of coaching education to the coach's philosophy emerged as a determinant for the pursuit of coaching education. When participants explained their coaching philosophy, it became evident that for some, their philosophy was both a motivator and a product of their recent educational pursuits. Additionally, online availability and continuity emerged as significant. Many agreed that their respective associations should develop and implement online support for coaches that can be engaged on a regular basis for the purpose of continuous engagement in training and follow up. Coaches seemed to agree that the courses are not in and of themselves inadequate but rather lacked the continuity necessary to ensure that coaches maintain the highest calibre of practice following their certification.

Perhaps the most significant of the finding was illuminated at the cross-section of the funding and experience perspectives. The apparent reluctance of sporting bodies to fund coaching education ventures emerged as a factor that greatly affects coaches' willingness to participate in coaching education. Several coaches expressed that more should be done from an institutional standpoint to ensure facilitators of the national programs are given the opportunity to enhance their skill and knowledge base. In the absence of this provision, responses seemed to suggest that coaches feel undervalued and simply have no interest in pursuing financial commitments which are neither mandatory nor will it improve their value to the organization. Coupled with the above is the held belief that experience, which requires no additional funding, significantly impacts coaching efficacy; $97.3 \%$ of participants admitted to having experience as a player within the sport of tennis with $52.63 \%$ stating that this experience was the factor that influenced their coaching style. Therefore, since the lessons of experience are not only invaluable but also free, it remains a major qualifier for practitioners.

\section{CONCLUSION}

Having completed the investigative process, what the results illustrated was not negative attitudes but rather the fact that courses may not be adequately catering to the needs of coaching practitioners in a meaningful way. Therefore, in order to address the issue of underperformance and encourage coach development via educational programs, more effort needs to be directed at meeting the educational needs of coaches. Additionally, issues such as disgruntlement of coaches who feel undervalued and inadequate exposure must be addressed in real and tangible ways. While exploration of this topic is by no means complete, there is now a better understanding that can guide future developmental efforts.

\section{REFERENCES}

Avner, Z., Markula, P., \& Denison, J. (2017). Understanding Effective Coaching: A Foucauldian Reading of Current Coach Ed... International Sport Coaching Journal, 4, 101109, https://doi.org/10.1123/iscj.2016-0108

Bloom, G. A., Durand-Bush, N., Schinke, R. J., \& Salmela, J. H. (1998). The importance of mentoring in the development of coaching and athletes. International Journal of Sport Psychology, 29, 267-281.

Cushion, C. J., Armour, K. M., \& Jones, R. L. (2003). Coach Education and Continuing Professional Development: Experience and Learning to Coach. Quest, 55(3), 215230, https://doi.org/10.1080/00336297.2003.10491800

Gilbert, W., Côté, J., \& Mallett, C. (2010). Developmental Paths and Activities of Successful Sport Coaches. Soccer Journal, 55(3), 10-12.

Nelson, L., Groom, R., \& Potrac, P. (2014). Research Methods in Sport Coaching. Routledge, https://doi.org/10.4324/9780203797549

Van Der Merwe, C., Malan, D. D. J., \& Willemse, Y. (2015). The state of teacher-coaches' sport-specific training, participation and coaching experience, mentor interaction and methods of continued education in sport coaching. African Journal for Physical, Health Education, Recreation \& Dance, 21(3:1), 733.

Vargas-Tonsing, T. (2007). Coaches' Preferences for Continuing Coaching Education. International Journal of Sports Science \& Coaching, 2(1), 25-35, https://doi.org/10.1260/174795407780367186

Werthner, P., \& Trudel, P. (2006). A new theoretical perspective for understanding how coaches learn to coach. SPORT PSYCHOLOGIST, 20(2), 198-212, https://doi.org/10.1123/tsp.20.2.198 
RECOMMENDED ITF TENNIS ACADEMY CONTENT (CLICK BELOW)

\title{
ITF Academy
}

\author{
Copyright (c) 2020 Kyle A. Hannays
}

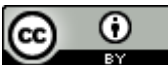

This text is under a Creative Commons BY 4.0 license

You are free to Share - copy and redistribute the material in any medium or format - and Adapt the content - remix, transform, and build upon the material for any purpose, even commercially under the following terms:

Attribution: You must give appropriate credit, provide a link to the license, and indicate if changes were made. You may do so in any reasonable manner, but not in any way that suggests the licensor endorses you or your use.

CCBY4.0 license terms summary CCBY4.0license terms 